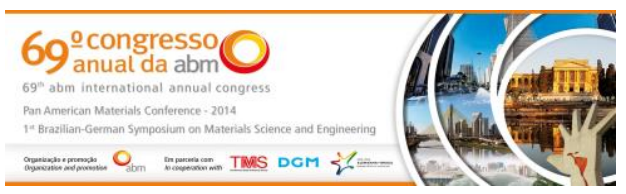

Tema: Soldagem

\title{
REDUÇÃO DO CUSTO DE TRANSFORMAÇÃO DA BQD PELA ALTERAÇÃO DOS PARÂMETROS DE SOLDA A TOPO POR CENTELHAMENTO*
}

\section{Resumo}

Douglas Luciano da Silva Oliveira ${ }^{1}$ Gabriel Santos Cunha² Yuri Soares Negreiros ${ }^{3}$ João Carlos Santos Delfino ${ }^{4}$

Em uma linha de decapagem contínua, o tempo de parada da entrada para realização da solda é um dos fatores que mais afeta a produtividade. Estratificandose o tempo total dessa parada, parte significativa é composta pelo tempo de centelhamento, que é um dos parâmetros fundamentais da soldagem a topo por centelhamento. Adicionalmente, a energia elétrica e o gás natural, consumidos durante o processo de soldagem, contribuem para onerar o custo de transformação da BQD. A fim de reduzir esse tempo e os custos de transformação, avaliou-se, através de análise metalográfica, ensaios de embutimento e dureza, a qualidade de juntas soldas com tempos reduzidos e sem o uso do sistema de depleção de oxigênio, para aços de baixo carbono, de acordo com referências da literatura. Com base nos resultados obtidos, foi possível reduzir o tempo médio de solda em $5 \mathrm{~s}$ em materiais com espessuras superiores a 2,50mm e eliminar a necessidade do uso de gás natural em todos os aços da GRADE 0, o que representa em torno de $76 \%$ das bobinas produzidas nas LDCs.

Palavras-chave: Soldagem a topo por centelhamento; Produtividade; Decapagem.

\section{REDUCING OF HOT ROLLED PICKLED COIL COSTS BY CHANGING IN FLASH WELDING PARAMETERS}

\section{Abstract}

In a continuous pickling line, the entry down time is one of the constraints in productivity. Stratifying the total down time, significant part consists in flashing time, which is one of the fundamental parameters of Flash Butt Welding. Furthermore, electricity and natural gas consumed during welding process, contribute to raise process costs. In order to reduce time and process costs was evaluated trough metallographic analysis, Olsen cup and hardness test, the quality of welds joints with diminished time and without oxygen depletion system for low-carbon steels according to the literature. Based on achieved results, it was possible to reduce the average weld time in $5 \mathrm{~s}$ for materials with thicknesses greater than $2.50 \mathrm{~mm}$ and eliminate the need of natural gas use in all GRADE 0 steels, which represents around $76 \%$ of coils processed in the CPLs.

Keywords: Flash butt welding; Productivity; Pickling.

1 Engenheiro de Materiais, USP, Mestre em Ciências, Engenheiro Especialista, GDA, CSN, Volta Redonda, RJ, Brasil.

2 Graduando em Engenharia Metalúrgica, UFF, Estagiário de Engenharia, GDA, CSN, Volta Redonda, RJ, Brasil.

3 Graduando em Engenharia Metalúrgica, UFCE, Estagiário de Engenharia, GDA, CSN, Volta Redonda, RJ, Brasil.

4 Técnico de Laboratório, GGPS, CSN, Volta Redonda, RJ, Brasil.

* Contribuição técnica ao $69^{\circ}$ Congresso Anual da ABM - Internacional e ao 14ํㅡㄹ ENEMET - Encontro Nacional de Estudantes de Engenharia Metalúrgica, de Materiais e de Minas, 21 a 25 de julho de 2014, São Paulo, SP, Brasil. 


\section{INTRODUÇÃO}

A soldagem a topo por centelhamento (Flash Butt Welding - FBW) é um processo de soldagem por resistência que apresenta diversas vantagens, tais como [1]: alta produtividade, preparação rápida e simplicidade de operação, não demandando mão de obra altamente qualificada. Este processo é utilizado em diversos segmentos da indústria, podendo se destacar principalmente nos setores automotivo, petroquímico e siderúrgico.

Na siderurgia, o processo FBW é amplamente utilizado em linhas de decapagem, a fim de se obter um processo contínuo através da união das extremidades das bobinas laminadas a quente na seção de entrada.

Os parâmetros de soldagem devem ser bem especificados e assertivos, pois, à eles estão atrelados a confiabilidade da junta soldada [2], além de grande influência sobre os indicadores de disponibilidade e produtividade das linhas. Isto significa que os parâmetros configurados devem estar de acordo com a composição química e a dimensão da chapa, de forma que a solda resista tanto as tensões trativas, compressivas e flexões nas linhas de decapagem, quanto as deformaçoes impostas na laminação à frio. Por outro lado, essa otimização também deve levar em consideração os fatores de custo atrelados à operação, a fim de aumentar a competitividade do produto final no mercado.

Com base em informações disponíveis na literatura, identificou-se a oportunidade de revisar os parâmetros de solda dos aços baixo carbono das Linhas de Decapagem Contínuas (LDCs) 3 e 4, objetivando reduzir o custo e o tempo das soldas realizadas [1-3].

\subsection{OBJETIVO}

Promover a redução do custo de transformação da BQD pela diminuição do tempo de centelhamento e inibição do gás de proteção, mantendo as propriedades físicas, químicas e metalúrgicas adequadas à confiabilidade e segurança da solda.

\subsection{Revisão Bibliográfica}

$\mathrm{Na}$ soldagem a topo por centelhamento [4-5] as peças a serem soldadas são posicionadas com as extremidades muito próximas, sem, no entanto, se tocarem. Então, uma corrente elétrica é acionada e uma das peças é colocada em movimento contra a outra de modo a se aproximarem com uma velocidade controlada. Este movimento de aproximação contínua e estabelece um fluxo de corrente, promovendo um aquecimento resistivo das superfícies das peças até que o ponto de fusão, inicialmente em poucos pontos de contato, do material seja alcançado. $O$ volume de material fundido é então expelido para fora da região da solda através de forças magnéticas superficiais criadas pelo fluxo de corrente, com a consequente formação de pequenas partes incandescentes de material sob a forma de centelhas. Por ação do centelhamento, ocorre a vaporização dos pontos em contato, permitindo, desta forma, que novos pontos entrem em contato e o centelhamento se espalhe ao longo de toda a superfície da junta. Após determinado tempo de centelhamento, quando todas as superfícies a serem unidas estiverem suficiente aquecidas, inicia-se a força de recalque, onde as peças são rapidamente pressionadas uma contra a outra, sofrendo considerável deformação plástica nas

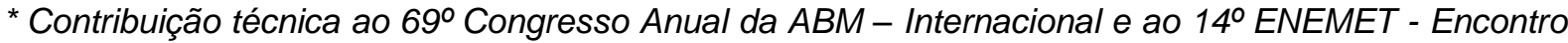
Nacional de Estudantes de Engenharia Metalúrgica, de Materiais e de Minas, 21 a 25 de julho de 2014, São Paulo, SP, Brasil.
} 


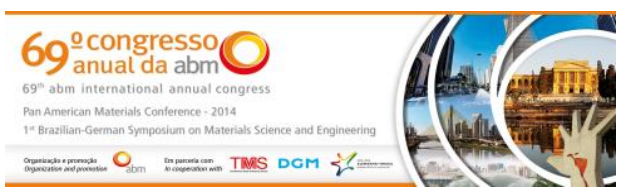

superfícies da junta o que leva a formação da solda ${ }^{2-5}$. Uma ilustração desse processo está indicada na Figura 1.

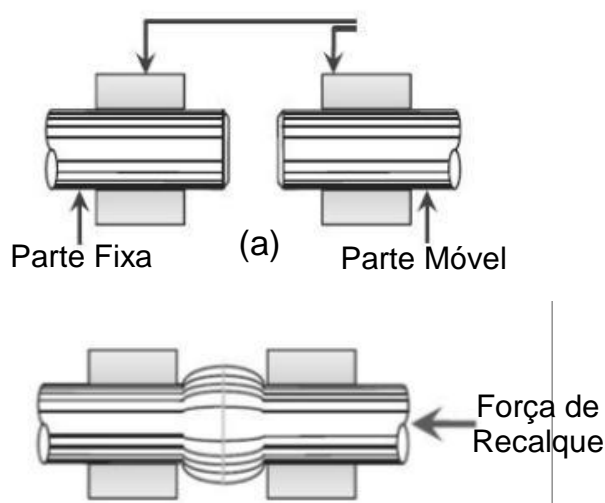

(c)

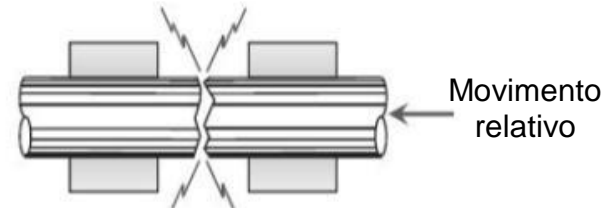

(b)

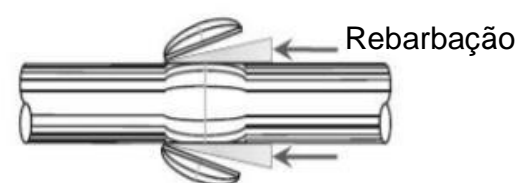

(d)

Figura 1. Etapas básicas para soldagem FBW. (a) Posicionamento inicial de fixação das peças, (b) Após a energia elétrica ser acionada, as peças são aproximadas com uma $v$, ocorrendo 0 centelhamento, (c) Aplicação da força de recalque para a formação da solda, (d) Rebarbação.

Fonte: Kim [6].

Adicionalmente, Ziemian [7] e Arabaci [8], demonstram que a qualidade desta junta soldada é diretamente influenciada pelos parâmetros de soldagem. O processo FBW possui uma complexa gama de parâmetros [2] a serem controlados de acordo com as especificações requeridas pela junta com o objetivo de garantir as propriedades mecânicas e evitar eventuais distorções, tensões residuais ou porosidade. Este controle é complexo devido as sucessivas alterações metalúrgicas que ocorrem durante e após o centelhamento ocasionado pelos diferentes níveis de calor entre a interface de solda, a ZTA - Zona Termicamente Afetada - e o metal base [9]. Da mesma forma, a composição química do metal base também exerce influência sobre os parâmetros, impactando na qualidade da junta [10].

\section{MATERIAL E MÉTODOS}

\subsection{Seleção do Material}

Os materiais processados nas LDCs da CSN são agrupados de acordo com os parâmetros estabelecidos de soldagem em oito grupos chamados "grades de solda". A triagem dos materiais para análise foi realizada tendo como critério de seleção a menor sensibilidade à variação dos parâmetros (melhor soldabilidade) e o maior volume de produção, visando obter um maior impacto no resultado global das LDCs. Através da apuração dos dados de produção, constatou-se que os materiais presentes na "grade 0", de acordo com a Figura 2, atenderiam este preceito.

* Contribuição técnica ao $69^{\circ}$ Congresso Anual da ABM - Internacional e ao 14ํㅡㄹ ENEMET - Encontro Nacional de Estudantes de Engenharia Metalúrgica, de Materiais e de Minas, 21 a 25 de julho de 2014, São Paulo, SP, Brasil. 

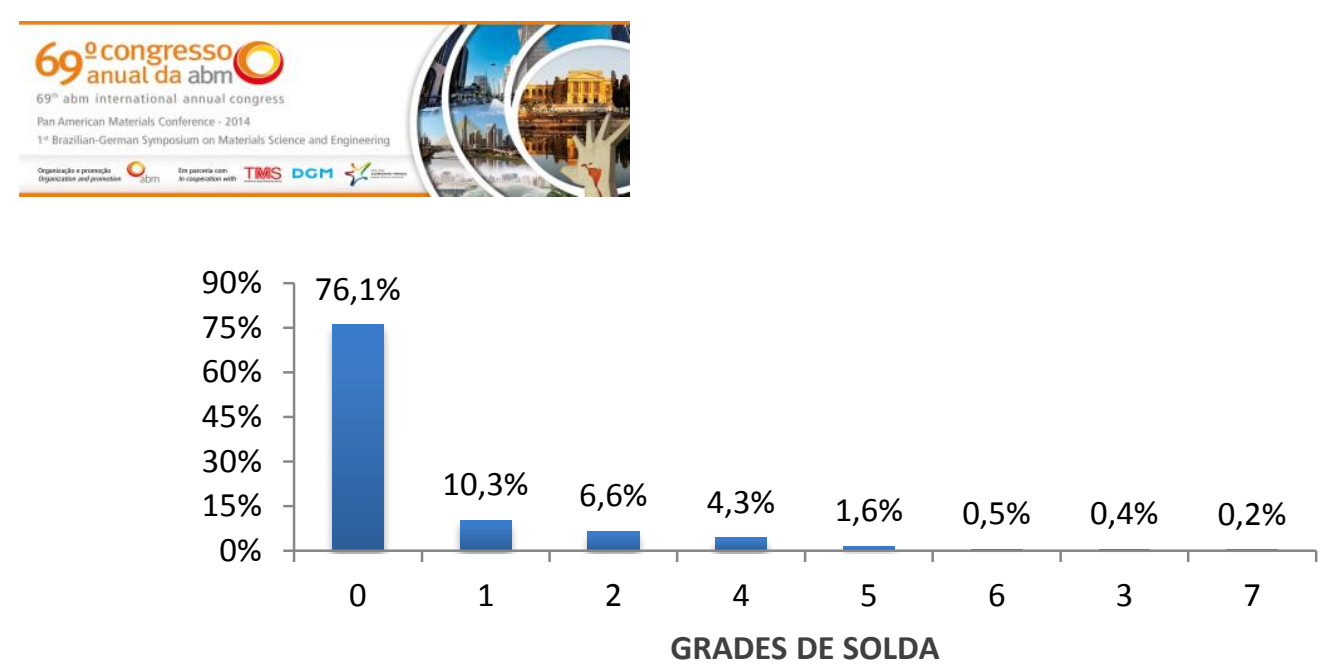

Figura 2. Gráfico com as parcelas de volume de produção (\%ton/ton) das grades de solda processadas nas LDCs. Fonte: CSN, Dados do Impromptu 2012

A seleção das espessuras seguiu a mesma premissa sendo designadas preliminarmente as espessuras de $2,25 \mathrm{~mm}, 3,00 \mathrm{~mm}$ e $4,25 \mathrm{~mm}$ para análise. Posteriormente se fez necessário o uso de uma amostragem de 2,00mm para realização de um planejamento de experimento - Design of Experiment (DOE).

\subsection{METODOLOGIA}

À luz de trabalhos como Resistance Welding Manuaß ${ }^{3}$ (RWMA), Welding Handbook [1] (WH) e informações de desenhos do fabricante para uma máquina similar às utilizadas nas LDCs 3 e 4, foi possível estabelecer um comparativo entre o cenário atual que se encontram as linhas de decapagem da CSN em relação aos tempos de centelhamento sugeridos por estes trabalhos conforme Tabela 1.

Tabela 1. Parâmetro Tempo de Centelhamento em segundos de acordo com cada faixa de espessura.

\begin{tabular}{c|c|c|c|c}
\hline $\begin{array}{c}\text { Faixas de } \\
\text { Espessura }\end{array}$ & $\begin{array}{c}\text { Parâmetro } \\
\text { Atual }\end{array}$ & Fabricante & WH & RWMA \\
\hline $1,27-1,50$ & 8 & 6 & 3,25 & 7,5 \\
\hline $1,51-1,75$ & 9 & 6 & 4 & 8 \\
\hline $1,78-2,01$ & 10 & 7 & 5 & 8,5 \\
\hline $2,02-2,26$ & 12 & 8 & 6 & 9 \\
\hline $2,27-2,51$ & 13 & 8 & 7 & 9 \\
\hline $2,52-3,02$ & 14 & 8 & 9 & 9,5 \\
\hline $3,03-3,53$ & 16 & 9 & 11 & 10 \\
\hline $3,54-4,04$ & 18 & 10 & 13 & 10 \\
\hline $4,05-4,55$ & 21 & 11 & 15 & 11 \\
\hline $4,56-5,05$ & 23 & 12 & 17 & 12 \\
\hline
\end{tabular}

Adotando uma postura mais conservadora, decidiu-se modificar o parâmetro atual conforme a Tabela 2 , incluindo a retirada do gás de proteção para se realizar os testes nas linhas de produção.

A justificativa pela decisão em não se utilizar o gás de proteção decorreu de que conceitualmente, o sistema de depleção de oxigênio com queima de gás natural foi desenvolvido para aprimorar solda em aços microligados e aços com teor de silício elevado [11]. Além disso, antes do modernização da máquina de solda em 2001, este insumo não era utilizado no processo de soldagem e bons resultados em aços baixo carbono já eram alcançados. Desta forma optou-se em analisar o impacto deste fator na qualidade da solda.

\footnotetext{
* Contribuição técnica ao 69 Congresso Anual da ABM - Internacional e ao 14 ENEMET - Encontro Nacional de Estudantes de Engenharia Metalúrgica, de Materiais e de Minas, 21 a 25 de julho de 2014,
} 


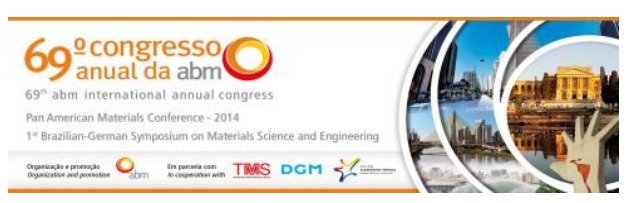

Tabela 2. Tabela de referência para alteração do Parâmetro

\begin{tabular}{|c|c|c|c|c|c|c|c|c|c|c|}
\hline $\begin{array}{c}\text { Faixas de } \\
\text { Espessura (mm) }\end{array}$ & $\begin{array}{c}1,27 \\
-\end{array}$ & $\begin{array}{c}1,51 \\
-\end{array}$ & $\begin{array}{c}1,78 \\
-\end{array}$ & $\begin{array}{c}2,02 \\
-\end{array}$ & $\begin{array}{c}2,27 \\
-\end{array}$ & $\begin{array}{c}2,52 \\
-\end{array}$ & $\begin{array}{c}3,03 \\
-\end{array}$ & $\begin{array}{c}3,54 \\
-\end{array}$ & $\begin{array}{c}4,05 \\
-\end{array}$ & $\begin{array}{c}4,56 \\
- \\
4,01\end{array}$ \\
\hline $\begin{array}{c}\text { Parâmetro Atual } \\
\text { (Com Gás Natural) }\end{array}$ & 8 & 9 & 10 & 12 & 13 & 14 & 16 & 18 & 21 & 23 \\
\hline $\begin{array}{c}\text { Parâmetro } \\
\text { Proposto } \\
\text { (Sem Gás Natural) }\end{array}$ & 6 & 6 & 7 & 8 & 8 & 9 & 11 & 13 & 15 & 18 \\
\hline
\end{tabular}

\subsection{Ensaios Laboratoriais}

Foram realizados ensaios de embutimento e dureza além de análises metalográficas e de linhas de fluxo.

Para a realização dos ensaios, foram retiradas 4 amostras, sendo 2 com o parâmetro atual e 2 com o parâmetro proposto. Em cada par de amostras foi realizado ensaio de embutimento em uma e na outra foram realizado os demais testes.

Foi feita a divisão em três seções, conforme a Figura 3, com intuito em avaliar quaisquer alterações que viessem a ocorrer ao longo da solda, para entender como a solda se comporta ao longo da amostra.

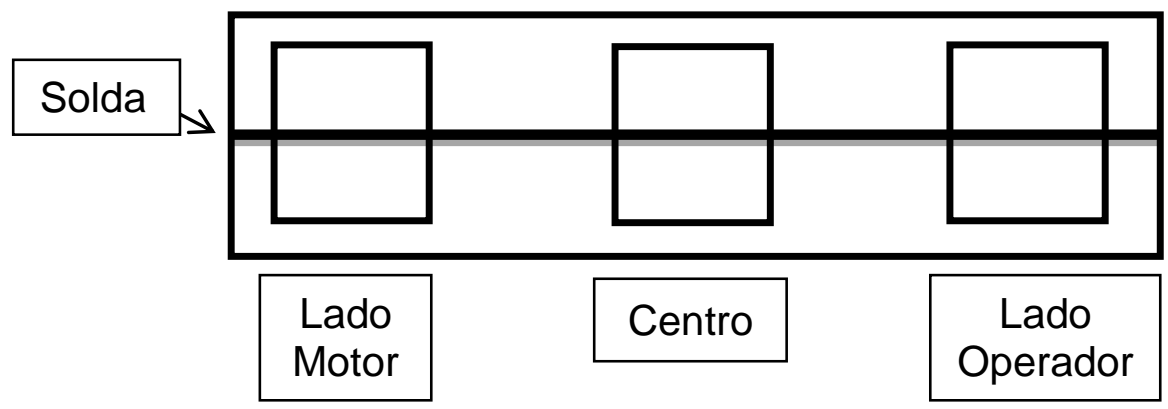

Figura 3. Esquema de corte de amostras para realização de ensaios

Para cada seção, o esquema de confecção de corpos de prova está descrito na Erro! Fonte de referência não encontrada.Figura 4.

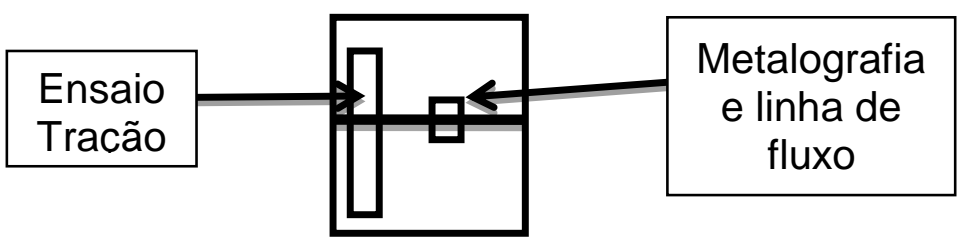

Figura 4. Confecção dos corpos de prova para realização de ensaios.

\subsubsection{Ensaios mecânicos}

Preliminarmente, foram realizados os ensaios de embutimento logo após o processo de soldagem nas LDCs, onde como forma de avaliação adotou-se o seguinte critério (ver Figura 5):

\footnotetext{
* Contribuição técnica ao $69^{\circ}$ Congresso Anual da ABM - Internacional e ao 14을 ENEMET - Encontro Nacional de Estudantes de Engenharia Metalúrgica, de Materiais e de Minas, 21 a 25 de julho de 2014, 

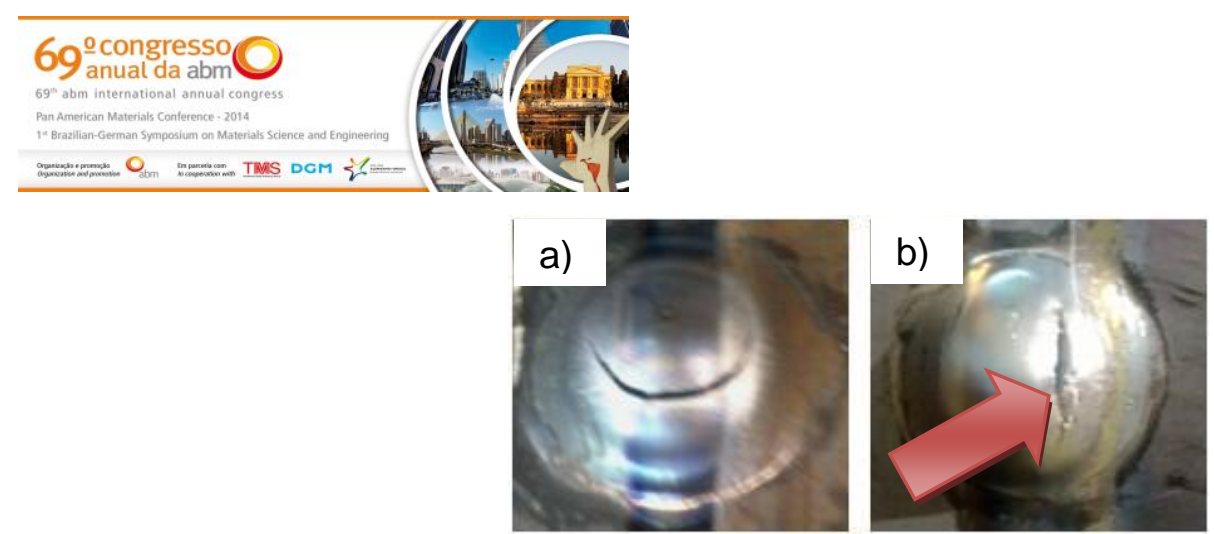

Figura 5. (a) Ruptura no sentido perimetral - APROVADO (b) Ruptura no sentido radial - REPROVADO

- Sem ruptura ou ocorrência de ruptura perimetral - APROVADO.

- Ocorrência de ruptura no sentido radial - REPROVADO.

A adoção deste método garante de forma preliminar, mesmo que de maneira não conclusiva, a avaliação da região da solda em relação ao metal base - MB.

Os ensaios de dureza Vickers seguiram as normas ASTM E $92-828^{12}$ no qual foram analisados ao todo 45 medições por amostra, sendo realizadas 15 medidas em cada região sendo 10 na região de solda e 5 no metal base.

Para tratamento dos resultados utilizou-se o software "Minitab" para a realização de teste de hipóteses. Assim, pode se definir estatisticamente se havia, ou não, diferença significativa nos valores de dureza entre as amostras.

\subsubsection{Ensaios metalográficos}

Para estes ensaios, o processo de lixamento foi realizado em politrizes giratórias utilizando lixas d'águas de granulometria de 100, 400 e 1200. Após este procedimento, as amostras foram submetidas a um polimento em pasta de diamante de $3 \mu \mathrm{m}$ e posteriormente em alumina $0,05 \mu \mathrm{m}$. Na realização do ataque químico, foi adotado nital 3\%.

$\mathrm{Na}$ realização dos ensaios de linhas de fluxo, foram utilizados os mesmos procedimentos, sendo que o ataque químico utilizado foi um reagente composto por $200 \mathrm{ml}$ de água destilada, $1 \mathrm{~g}$ de cloreto férrico, $2,9 \mathrm{~g}$ de ácido pícrico e $20 \mathrm{ml}$ de detergente neutro. Para a preparação deste reagente, se misturou manualmente todos os compostos químicos até a completa dissolução dos compostos para então realizar um aquecimento até uma temperatura de $80^{\circ} \mathrm{C}$ e, em seguida, resfriá-lo até $50^{\circ} \mathrm{C}$, para neste momento imergir a amostra na solução por aproximadamente 30 segundos.

\subsubsection{Planejamento de experimento}

No decorrer do projeto, em posse de alguns resultados prévios não satisfatórios apresentados pelas alterações propostas à amostra de $2,25 \mathrm{~mm}$, optou-se por uma nova bateria de testes para a realização de um $D O E$, a fim de identificar a significância das variáveis e suas interações.

A espessura selecionada para representar a faixa $<2,52 \mathrm{~mm}$ foi a de $2,00 \mathrm{~mm}$, na qual foram realizados experimentos multivariados em sequência aleatória nos fatores "utilização do gás" e "tempo de centelhamento", de acordo com a Tabela 3.

Tabela 3. Amostragem adotada para o DOE

\begin{tabular}{|c|c|c|c|c|c|c|c|c|}
\hline Ordem & 1 & 2 & 3 & 4 & 5 & 6 & 7 & 8 \\
\hline Gás & Sem & Sem & Com & Com & Com & Sem & Sem & Com \\
\hline $\begin{array}{c}\text { Tempo de } \\
\text { Centelhamento }\end{array}$ & 7 & 7 & 10 & 10 & 7 & 10 & 10 & 7 \\
\hline
\end{tabular}

As variáveis resposta da análise por DOE foram obtidas a partir da realização de ensaios de embutimento controlados nas soldas, onde foi mensurada a profundidade

\footnotetext{
* Contribuição técnica ao 69 Congresso Anual da ABM - Internacional e ao 14 ENEMET - Encontro Nacional de Estudantes de Engenharia Metalúrgica, de Materiais e de Minas, 21 a 25 de julho de 2014, 
de penetração, a carga máxima e o percentual de aprovação de cada combinação testada.

\section{RESULTADOS E DISCUSSÃO}

Os resultados obtidos com os ensaios de Embutimento em campo estão demonstrados na Tabela 4.

Tabela 4. Resultados obtidos do ensaio de embutimento.

\begin{tabular}{|c|c|c|c|c|c|c|}
\hline \multirow{2}{*}{$\begin{array}{c}\text { Espessura } \\
(\mathrm{mm})\end{array}$} & \multicolumn{2}{|c|}{ Lado Operador } & \multicolumn{2}{c|}{ Centro } & \multicolumn{2}{c|}{ Lado Motor } \\
\cline { 2 - 7 } & Atual & Proposto & Atual & Proposto & Atual & Proposto \\
\hline 2,25 & Aprovado & Aprovado & Aprovado & Aprovado & Aprovado & Aprovado \\
\hline 3,00 & Aprovado & Aprovado & Aprovado & Aprovado & Aprovado & Aprovado \\
\hline 4,25 & Aprovado & Aprovado & Reprovado & Aprovado & Reprovado & Aprovado \\
\hline
\end{tabular}

É possível observar na Tabela 4 que, nas amostras de 4,25mm, amostras soldadas no parâmetro atual foram reprovados. Esse fato pode ser explicado por uma combinação entre parâmetros não ideais e eletrodo em fim de vida útil. Alterando o parâmetro de solda, mesmo com o eletrodo em fim de vida útil a solda se mostrou mais confiável.

As Figuras 6,7 e 8 mostram as micrografias da interface de solda das amostras $2,25 \mathrm{~mm}, 3,00 \mathrm{~mm}$ e $4,25 \mathrm{~mm}$, respectivamente.

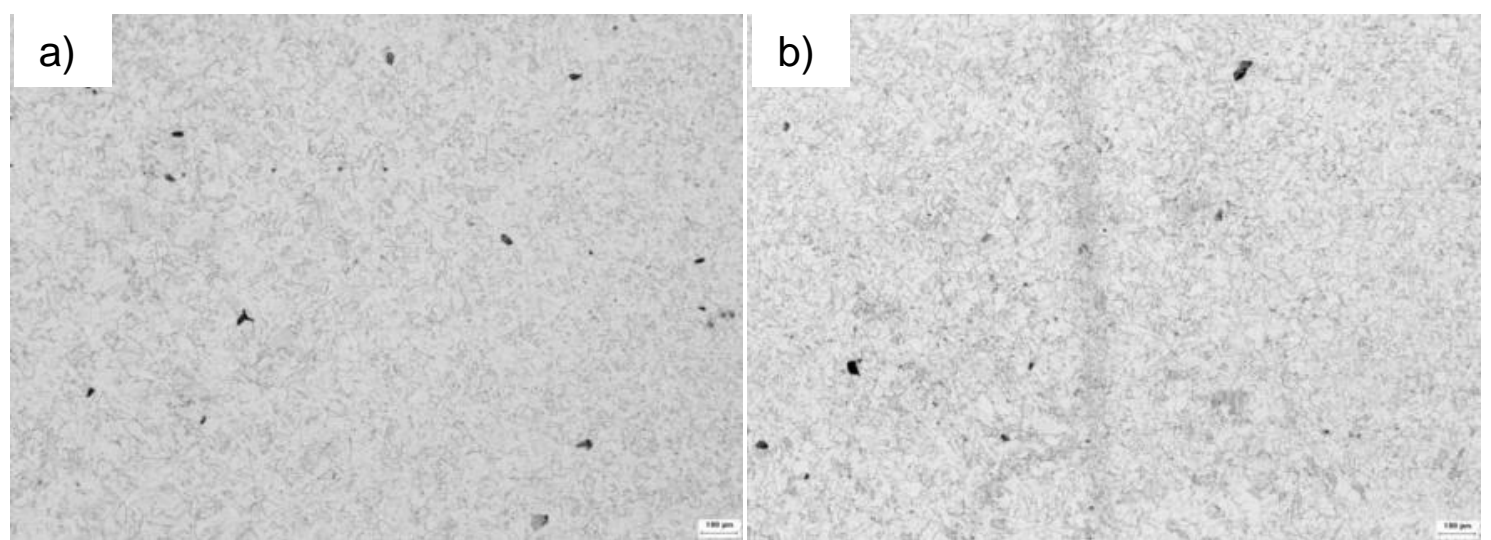

Figura 6 - Micrografias da interface de solda da amostra de 2,25mm. a) parâmetro atual centro; b) Parâmetro proposto centro.

$\mathrm{Na}$ amostra de $2,25 \mathrm{~mm}$, tanto o parâmetro proposto quanto o parâmetro atual mostraram uma fase ferrítica em toda a sua área. Nota-se uma interface de solda mais pronunciada no parâmetro proposto que no parâmetro atual.

\footnotetext{
* Contribuição técnica ao 69 Congresso Anual da ABM - Internacional e ao 14 ENEMET - Encontro Nacional de Estudantes de Engenharia Metalúrgica, de Materiais e de Minas, 21 a 25 de julho de 2014, 

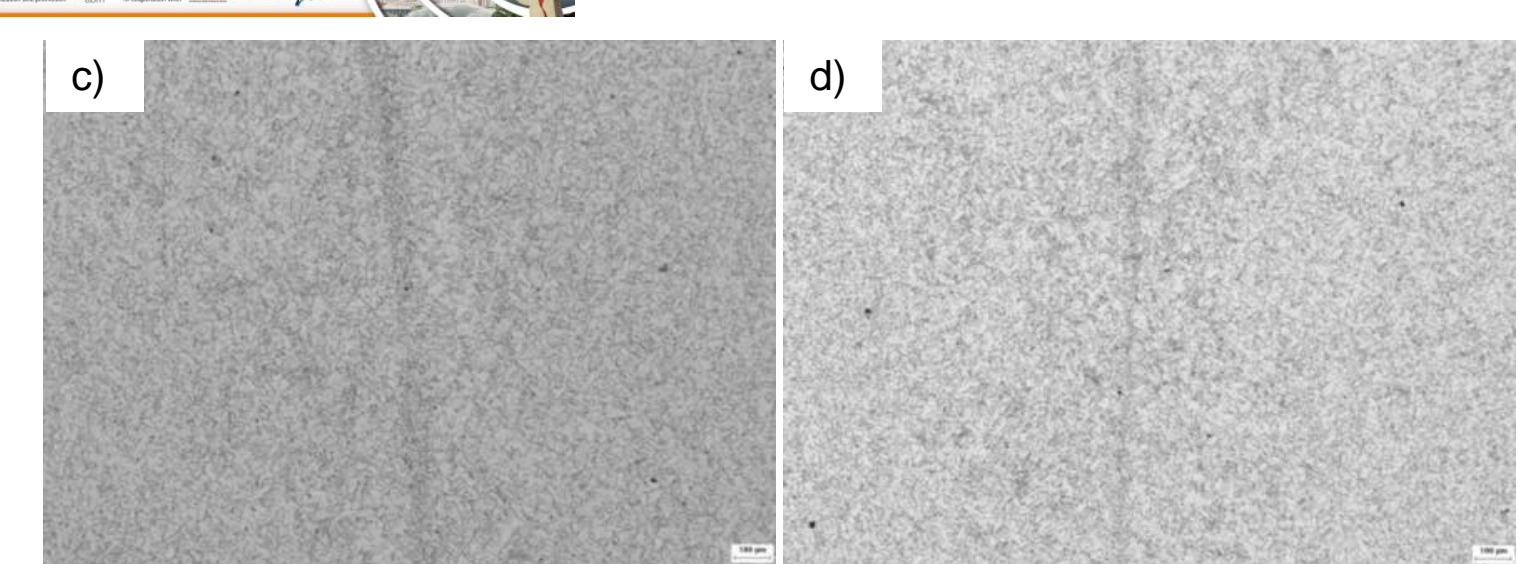

Figura 7 - Micrografias da interface de solda da amostra de 3,00mm. a) parâmetro atual centro; b) Parâmetro proposto centro.

$\mathrm{Na}$ amostra de $3,00 \mathrm{~mm}$ também se tem uma fase ferrítica por toda a solda independente do seu parâmetro. Nota-se que houve um maior refino de grão na interface da solda do parâmetro proposto, indicando uma melhora de suas propriedades mecânicas.
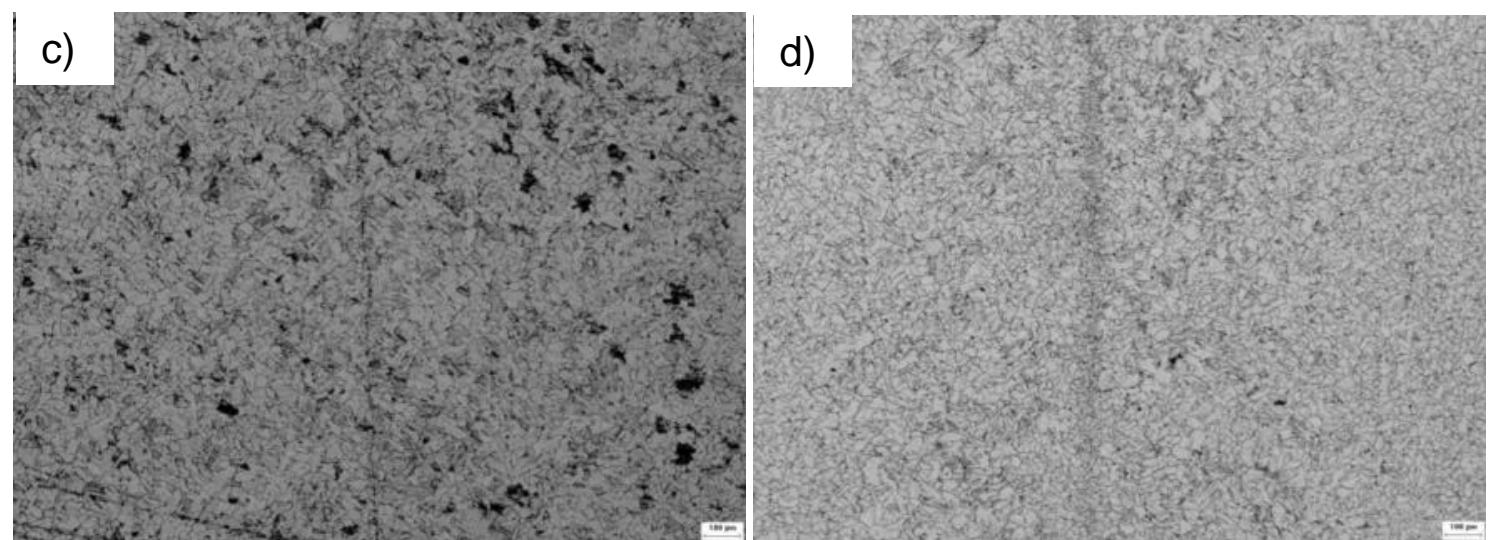

Figura 8 - Micrografias da interface de solda da amostra de 4,25mm. a) parâmetro atual centro; b) Parâmetro proposto centro.

Como nas demais amostras, também apresenta uma fase predominantemente ferrítica, porém, com uma interface de solda mais destacada no parametro atual. Nas amostras do parâmetro atual podem ser visualizads algumas inclusões de oxidos alinhadas à interface. Estas, atuam como concentradores de tensão na solda e, comparando-se com os resultados da Tabela 4, podem justificar a reprovação das amostras no ensaio de embutimento. Além disso, foi possível observar um maior refino de grão com o parâmetro proposto. As análises de linha de fluxo podem ser vistas nas Figuras 9, 10 e 11 a seguir:
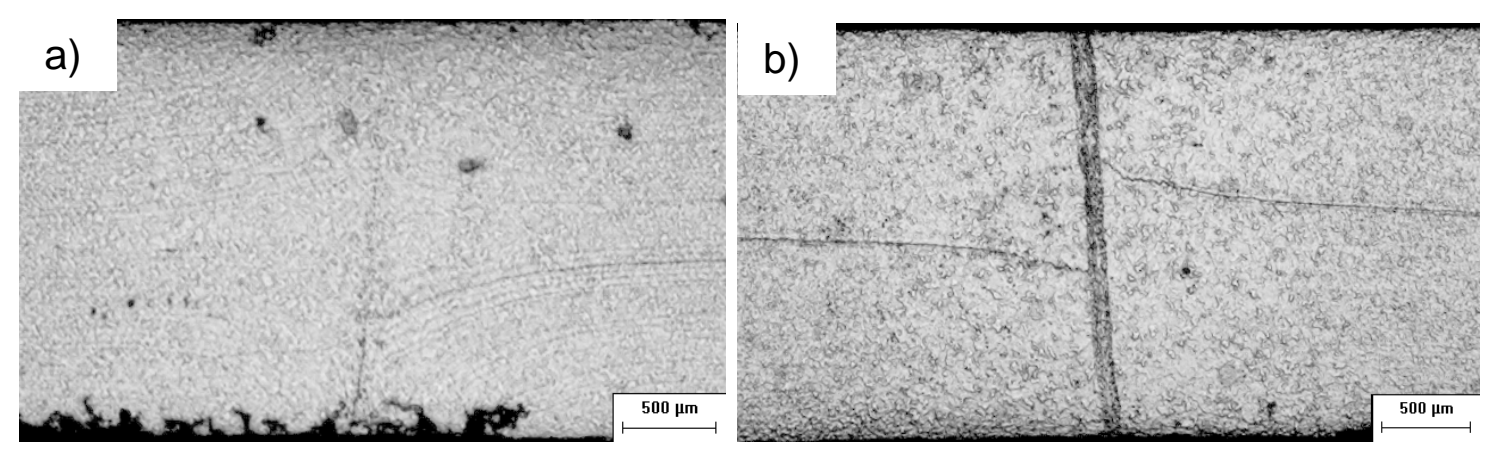

Figura 9 - Linha de fluxo da amostra centro 2,25mm. a) parâmetro atual; b) Parâmetro proposto.

\footnotetext{
* Contribuição técnica ao 69ำ Congresso Anual da ABM - Internacional e ao 14ํㅡㄹ ENEMET - Encontro Nacional de Estudantes de Engenharia Metalúrgica, de Materiais e de Minas, 21 a 25 de julho de 2014, 
$\mathrm{Na}$ amostra de $2,25 \mathrm{~mm}$, na analise de linhas de fluxo, nota-se que no parâmetro atual a interface esta mais pronunciada. Isto pode significar uma maior concentração de energia neste ponto, consequentemente, uma maior concentração de defeitos.

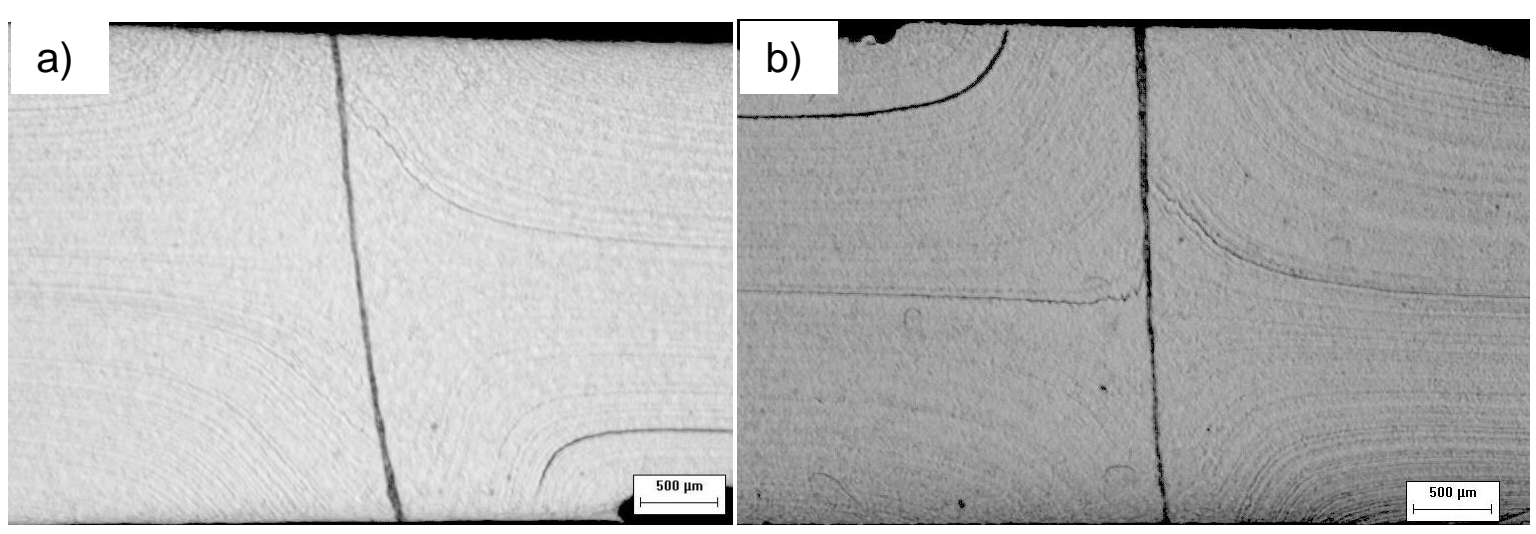

Figura 10 - Linha de fluxo da amostra centro 3,00mm. a) parâmetro atual; b) Parâmetro proposto.

Nas amostras de 3,00mm a interface mais pronunciada ocorre no parâmetro atual e não no parâmetro proposto. As linhas de fluxo se mostraram coerentes entre si, não apresentando diferenças significativas entre os dois parâmetros.
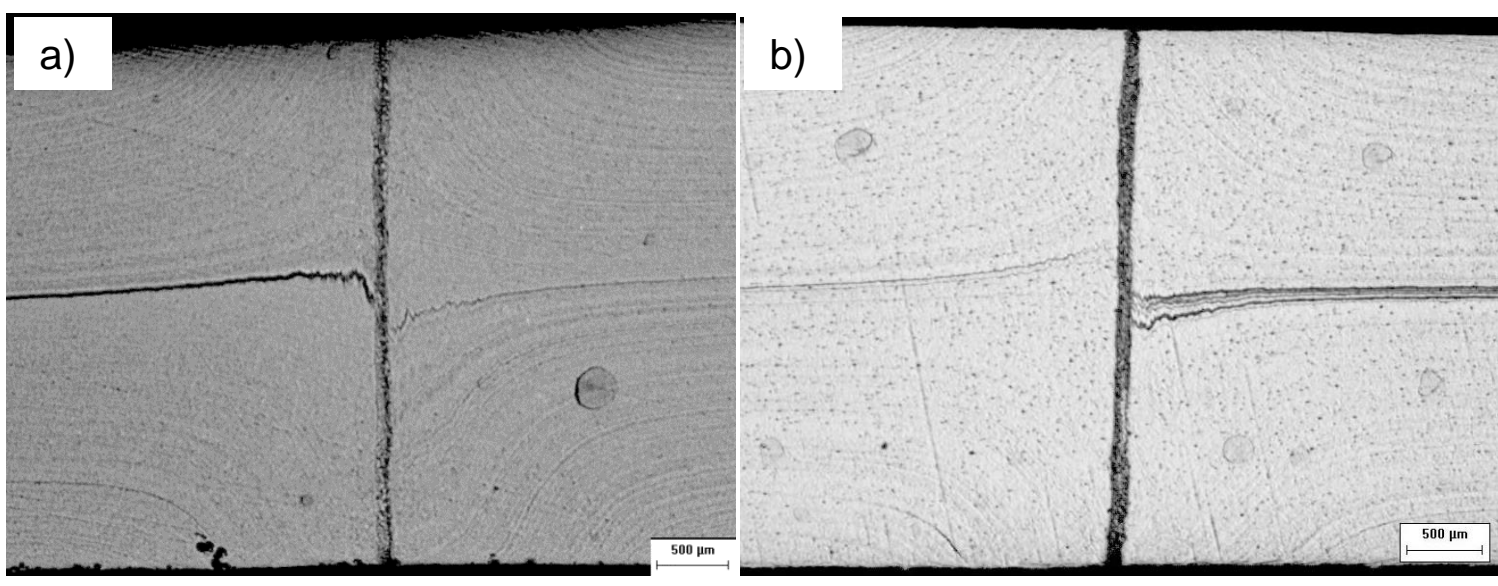

Figura 11 - Linha de fluxo da amostra centro 4,25mm. a) parâmetro atual; b) Parâmetro proposto.

$\mathrm{Na}$ amostra $4,25 \mathrm{~mm}$, as linhas de fluxo do parametro atual estão com uma angulatura muito severa, indicando possivelmente um recalque inadequado. Já no parametro proposto, o ângulo das linhas de escoamento se aproxima do ideal de $45^{\circ}$ para o processo. Isto garante uma melhor qualidade de solda, devido ao escoamento adequado de impurezas da interface para fora do cordão durante o recalque.

A partir destes resultados, a Tabela 5 sintetiza o consenso dos membros envolvidos no projeto, para a avaliação da implantação do parametro proposto para testes em escala industrial.

Tabela 5. Comparativo dos resultados do Parâmetro Proposto em relação ao Atual.

\begin{tabular}{|c|c|c|c|c|}
\cline { 2 - 5 } \multicolumn{1}{c|}{} & Metalografia & Linhas de fluxo & Embutimento & Resultado \\
\hline $2,25 \mathrm{~mm}$ & $\boldsymbol{x}$ & $\boldsymbol{x}$ & $\checkmark$ & REPROVADO \\
\hline $3,00 \mathrm{~mm}$ & $\checkmark$ & $\checkmark$ & $\checkmark$ & APROVADO \\
\hline $4,25 \mathrm{~mm}$ & $\checkmark$ & $\checkmark$ & $\checkmark$ & APROVADO \\
\hline
\end{tabular}

De acordo com a Tabela 5, a amostra de 2,25mm, utilizando o parâmetro proposto do tempo de centelhamento, apresentou um desempenho inferior ao parâmetro usado

* Contribuição técnica ao 69ํㅡㄴ Congresso Anual da ABM - Internacional e ao 14 ENEMET - Encontro Nacional de Estudantes de Engenharia Metalúrgica, de Materiais e de Minas, 21 a 25 de julho de 2014, 


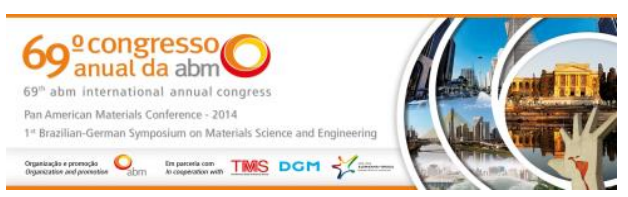

atualmente nas linhas de produção. Através desta análise prévia, optou-se por não se realizar os ensaios de dureza nesta amostra devido aos resultados apresentados.

Nas demais, a partir dos resultados de dureza Vickers e utilizando o software Minitab, realizou-se um teste de hipóteses, que se basea na análise de variâncias para se estudar a diferença entre médias de duas ou mais populações. A regra de decisão basea-se no valor de $\mathrm{p}$ ( $p$-value) que deve ser comparado ao nível de significância adotado. No caso, para valores de $\mathrm{p}>0,05$ não há diferença significativa entre as médias dos resultados, caso contrario há diferença. Constatou-se para a amostragem de 3,00mm que não houve variação significativa nos valores de dureza na região da solda entre os dois parâmetros utilizados conforme Figuras 12Figura.

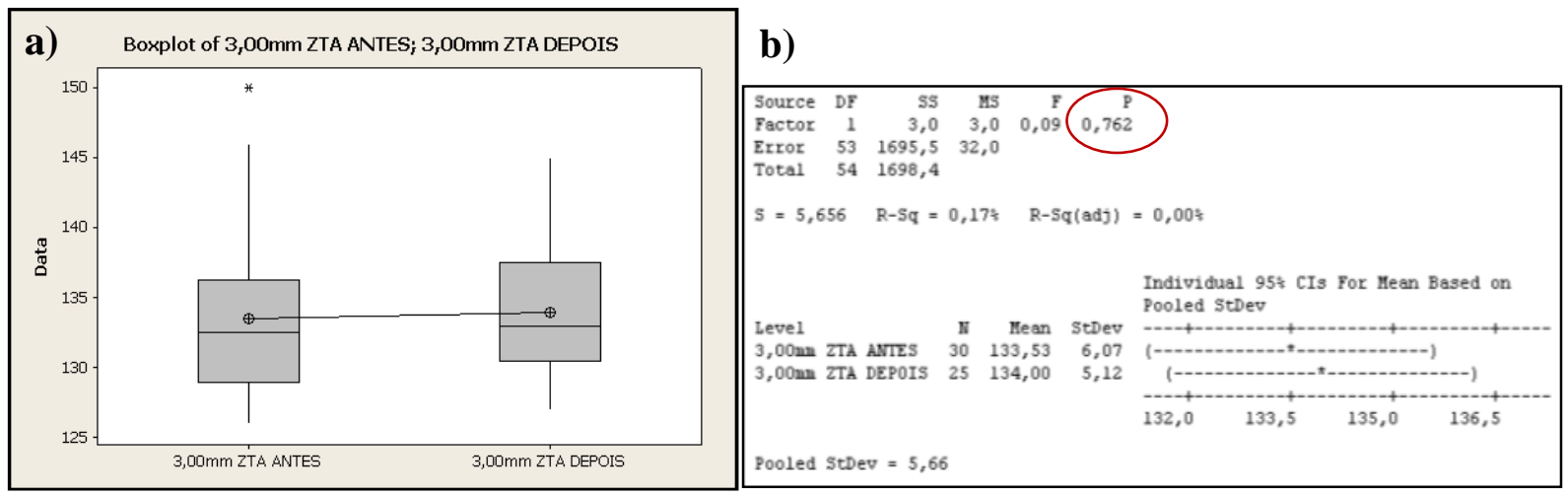

Figura 12. Resultados do Minitab do ensaio de dureza na interface da solda amostra 3,00mm. a) Distribuição dos resultados; b) Resultado do teste de hipóteses. Fonte: Minitab 16

Os resultados evidenciados na Figura 13 das amostras de 4,25mm mostraram a existência de variação significativa entre as soldas realizadas nos dois parâmetros, entretanto, a diferença foi justificada pela própria diferença de dureza do metal base.

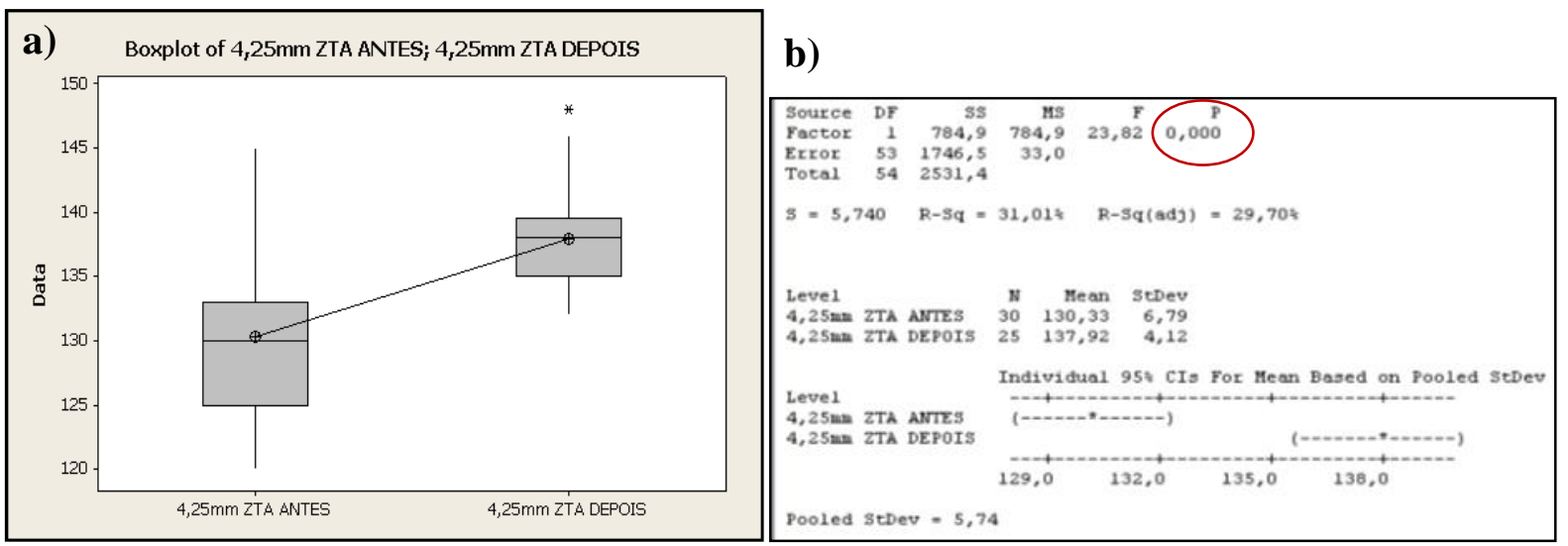

Figura 13. Resultados do Minitab do ensaio de dureza na interface da solda amostra 4,25mm. a)

Distribuição dos resultados; b) Resultado do teste de hipóteses. Fonte: Minitab 16

A partir disto foi feita a análise quantitativa dos resultados, objetivando mensurar o aumento percentual de valor de dureza na região da ZTA em relação ao MB.

A ZTA pelo critério proposto sofreu um incremento de dureza inferior ao atual - ver Tabela 6. 
3 Resistence Welder Manufacturers RWMA, Resistence Welding Manual, ed. 4, p.516, 2003.

4 Modenesi PJ. Introdução aos Processos de Soldagem. Ed. UFMG Belo Horizonte, p.37, 2006.

5 Filho OG. Influencia da corrente elétrica, da força de recalque e do tratamento térmico de revenimento na soldagem a topo a topo por centelhamento de serras de fita bimetálica. USP São Paulo, 2007, p.45.

6 Kim DC, So WJ, Kang MJ. Effect of flash butt welding parameters on weld quality of mooring chain. Archives of materials science and engineering, 2009; 39: 113.

7 Ziemian CW, Sharma MM, Whaley DE. Effects of flashing and upset sequences on microstructure hardness, and tensile properties of welded structural steel joints. Materials and Design V.33, Ed. Elsevier Ltd, 2011, p.1-5.

8 Arabaci U, Çetînkaya C, Akay A. An Investigation of Effects of Upsetting Current Time and Normalization Heat treatment on Mechanical Properties of X40CrMoV5 1 and C1030 steels Joined by Flash Butt Welding. Materials and Design V.28. Ed. Elsevier Ltd., 2006, p. 2351-2360.

9 Ghosh PK, Gupta PC, Pal OM, Avtar, Jha BK, Dwivedi VS. Influence of weld thermal cycle on properties of Flash Butt Welded Mn-Cr-Mo Dual Phase Steel. ISIJ International, 1993; 33: 807-815, 1993.

10 Yurioka N. Physical Metallurgy of Steel Weldability. ISIJ International, 2000; 4: 566-570.

11Training Manual - 62" Combination Flash Butt Welder Upgrades for Pickle Line \#3, Companhia Siderurgica Nacional

12 ASTM E92 - 82 (Reapproved 2003): Standard Test Method for Vickers Hardness of Metallic Materials. 